AAV vectors and cardiovascular disease

\section{Targeting TNF receptor in the heart: clue to way forward with AAV?}

RJ Hajjar and K Zsebo

Gene Therapy (2007) 14, 1611-1612; doi:10.1038/sj.gt.3303047; published online 18 October 2007

In the last few years, adeno-associated vectors (AAV) have generated significant interest as safe and effective vehicles for gene transfer. In the cardiovascular field, there has been considerable enthusiasm for AAV because of their small size, which allows them to pass through vessel walls and to reach the myocardium, and for their promise of a relatively long-term payload gene expression. However, there have been two reported examples of dose-dependent generation of $\mathrm{CD}^{+} \mathrm{T}$-cell responses to AAV capsid proteins in humans, limiting the therapeutic potential of otherwise promising therapies for hemophilia $^{1}$ and type I hypertriglyceridemia deficiency ${ }^{2}$.

The study by McTiernan et al. ${ }^{3}$ in this issue comparing the effects of gene transfer of type 2 AAV (AAV2) encoding TNFRII-Fc with empty AAV2 capsids may provide some clue to new pathways controlling the delicate balance between induction of deleterious $\mathrm{T}$-cell responses and operational immune tolerance to the AAV2 and payload gene proteins. These experiments in the baboon were initially performed as pre-clinical safety studies of AAV2 TNFRII-FC gene therapy as a therapy for heart failure. Although the potential value of this approach as heart-failure therapy has since been reconsidered based on other results, the observations by McTiernan et al. ${ }^{3}$ that myocarditis resulted following the injection of AAV2 encoding TNFRII-Fc but not AAV2 empty capsids in the heart of baboons may have broad implications for AAV-based gene therapy.

The authors attempt to sort through three reasons why myocarditis might occur:

1. immune response directed toward AAV capsids;

2. immune response directed toward the transgene: TNFRII-Fc; and
3. biological response induced by TNFRII-Fc.

Overall, this is an interesting and difficult study performed in a preclinical setting for therapeutics (TNFRIIFc). The authors stumble on a surprising finding, and with the limited number of baboons they conduct a number of serological and histological measurements in an attempt to explain the findings. Their results seem to rule out an immune response directed toward the transgene: TNFRII-Fc. However, based on the data provided, we do not agree with their conclusion suggesting that myocarditis represents a general phenomenon of cellular responses to all AAV vectors encoding foreign proteins. An alternative explanation is that the combination of anti-TNF coding transgenes and AAV results in cellular immune responses against AAV capsid proteins that would not occur otherwise. This alternative hypothesis is supported by the following:

(1) AAV vectors delivering the transgene for the sarcoplasmic reticulum ATPase2a have been studied in sheep, pig and primates, with no evidence of myocarditis, T-cell infiltrates or damage to cardiac tissue, as assessed by histopathological analysis or highly sensitive assays for cardiac enzymes. ${ }^{4-5}$

(2) Operational tolerance to the product of foreign transgenes following in vivo gene transfer of AAV vectors is associated with CD4+ T-cell tolerance involving anergy and deletion mechanisms. This has been demonstrated for Factor IX in primates $^{6}$ and ovalbumin in mice. ${ }^{7}$ In both cases, the critical role of $\mathrm{CD}^{+} \mathrm{CD} 25^{+} \mathrm{T}$ regulatory cells has been demonstrated.

(3) Latency induced by viral infections are attributed to the generation of $\mathrm{CD} 4{ }^{+} \mathrm{CD} 25^{+} \mathrm{T}$ regulatory cells, ${ }^{8}$ and the critical role of TNF in the generation of such $\mathrm{T}$ regulatory cells has recently been elucidated, ${ }^{9}$ suggesting a biological link in the study by McTiernan et al. ${ }^{3}$ between antiTNF therapy and the generation of myocarditis.

(4) Experimental support for our alternative hypothesis in primates is provided in the study by Mingozzi et al., ${ }^{6}$ where generation of humoral immune responses was studied when immunosuppressive agents were combined with an AAV2-hF.IX vector (Figure 1). ${ }^{6}$ Antibody responses against AAV2 capsid proteins were significantly blunted with the administration of mycophenolate mofetil (MMF) and sirolimus; however, when daclizumab (a humanized antiCD25 antibody) was added to this regimen, the anti-AAV2 antibody response was higher than in non-immunosuppressed animals. This suggests that a $\mathrm{CD} 4^{+} \mathrm{CD} 25^{+}$ $T$ regulatory pathway is active in the operational tolerance documented to AAV capsid proteins.

Therefore, the biological consequence of locally inhibiting TNF signaling may have resulted in myocarditis in the study by McTiernan et $a l .^{3}$ In this alternative model, local inhibition of TNF prevents the generation of tolerogenic anti-AAV capsid $\mathrm{CD} 4{ }^{+} \mathrm{CD} 25^{+} \mathrm{T}$ cells with subsequent enhancement of a cellular immune response against the AAV capsid antigens. In other words, blocking TNF (and subsequent prevention of $\mathrm{T}$ regulatory cell development) may have been enough to tip the balance of an immune response to AAV vector triggered initially by local innate immunity toward a destructive cellular immune response and myocarditis.

Our overall conclusions also differ from those of the authors. We do not believe that these data are discouraging to the field of AAV gene therapy. Rather, we are encouraged by these findings, as they potentially provide clues for further manipulating the immune system with modalities that may enhance the success of AAV therapeutics. For example, the use of agents such as sirolimus may be of benefit as this drug has been shown to promote the 




Figure 1 Anti-AAV2 antibody formation following AAV2-hF.IX vector delivery from Mingozzi et al. Time 0 represents the time of vector administration; dotted vertical line shows the time when immunosuppression (IS) was withdrawn. All animals received $8 \times 10^{12}$ viral genomes per $\mathrm{kg}$ of an AAV-2-hF IX vector infused through the hepatic artery. Each line represents the average value (+s.d.) of a group of three animals. This figure was initially published in Mingozzi F, Hasbrouck NC, Basner-Tschkarajan E, Edmonson SA, Hui DJ, Sabatino DE et al. Modulation of tolerance to the transgene product in a non-human primate model of AAV-mediated gene transfer to liver. Blood 2007; e-pub ahead of print 3 July 2007.

induction of regulatory $\mathrm{T}$ cells. ${ }^{10-12}$ Finally, recent studies in animal models have shown that adoptive transfer of $\mathrm{CD} 4{ }^{+} \mathrm{CD} 25^{+} \mathrm{T}$ regulatory cells can prevent or even cure allergic and autoimmune diseases and the cells appear to induce transplantation tolerance. ${ }^{13}$ Thus, we hope that these new data by McTiernan et al. ${ }^{3}$ stimulate new thinking regarding the immunology of AAV vectors and the critical importance of understanding the possible effect due to the biological activities of payload genes on the local and systemic environments.

Professor RJ Hajiar is at the Cardiovascular Research Center, Mount Sinai School of Medicine, New York, NY, USA, and K Zsebo is at the Celladon Corporation, La Jolla, CA, USA. E-mail:roger.hajjar@mssm.edu Published online 18 October 2007
1 Manno CS, Pierce GF, Arruda VR, Glader B, Ragni M, Rasko JJ et al. Successful transduction of liver in hemophilia by AAV-Factor IX and limitations imposed by the host immune response. Nat Med 2006; 12: 342-347.

2 Mingozzi F, Muelenberg J, Hui D, Basner-Tschakarajn E, de Pos P, High KA. Intramuscular Administration of an AAV1 Vector in Humans Results in Capsid Specific T cell Responses. Mol Ther 2007; 15 (Suppl 1): 3400, \#1056.

3 McTiernan CF, Mathier MA, Zhu X, Xiao $\mathrm{X}$, Klein $\mathrm{K}$, Swan $\mathrm{CH}$ et al. Myocarditis following adeno-associated viral expression of human soluble TNF receptor (TNFRII-Fc) in baboon hearts. Gene Therapy 2007.

4 Preovolos AC, Mennen MT, Bilney A, Mariani J, Kaye DM, Power JM. Development of a novel perfusion technique to allow targeted delivery of gene therapy-the V-Focus system. I Extra Corpor Technol 2006; 38: 51-52.

5 Ly HQ, Kawase Y, Prunier F, Lebeche D, Shi Y, Yoneyama R et al. Cardiac function improvement following in vivo intracaoroanry adeno-associated virus type 1 vector gene transfer of SERCA2a in a pre-clinical model of heart failure. Circulation 2007; 116: 321.

6 Mingozzi F, Hasbrouck NC, BasnerTschkarajan E, Edmonson SA, Hui DJ, Sabatino DE et al. Modulation of tolerance to the transgene product in a nonhuman primate model of AAV-mediated gene transfer to liver. Blood 2007; 110: 2334-2341.

7 Cao O, Dobrzynski E, Wang L, Nayak S, Mingle B, Terhorst C et al. Induction and role of regulatory CD4+CD25+ $\mathrm{T}$ cells in tolerance to the transgene product following hepatic in vivo gene transfer. Blood 2007; 110: 1132-1140.

8 Raghavan S, Holmgren J. CD4+CD25+ suppressor $\mathrm{T}$ cells regulate pathogen induced inflammation and disease. FEMS Immunol Med Microbiol 2005; 44: 121-127.

9 Chen X, Baumel M, Mannel DN, Howard OM, Oppenheim JJ. Interaction of TNF with TNF receptor type 2 promotes expansion and function of mouse $\mathrm{CD} 4+\mathrm{CD} 25+\mathrm{T}$ regulatory cells. I Immunol 2007; 179: 154-161.

10 Battaglia M, Stabilini A, Roncarolo MG. Rapamycin selectively expands CD4+CD25+FoxP3+ regulatory $\mathrm{T}$ cells. Blood 2005; 105: 4743-4748.

11 Battaglia M, Stabilini A, Migliavacca B, Horejs-Hoeck J, Kaupper T, Roncarolo MG. Rapamycin promotes expansion of functional $\mathrm{CD} 4+\mathrm{CD} 25+\mathrm{FOXP3}+$ regulatory $\mathrm{T}$ cells of both healthy subjects and type 1 diabetic patients. J Immunol 2006; 177: 8338-8347.

12 Battaglia M, Stabilini A, Draghici E, Gregori S, Mocchetti C, Bonifacio E et al. Rapamycin and interleukin-10 treatment induces $\mathrm{T}$ regulatory type 1 cells that mediate antigen-specific transplantation tolerance. Diabetes 2006; 55: 40-49.

13 Jiang S, Lechler RI. CD4+CD25+ regulatory T-cell therapy for allergy, autoimmune disease and transplant rejection. Inflamm Allergy Drug Targets 2006; 5: 239-242. 